\title{
The Introductory Psychology Text and Cross-Cultural Psychology: Beyond Ekman, Whorf, and Biased I.Q. Tests
}

Walt Lonner

Western Washington University, Bellingham,WA, walt.lonner@wwu.edu

Follow this and additional works at: https://scholarworks.gvsu.edu/orpc

Acknowledgment: Much of the work on this part of the project was done by Elke Rumpel as her master's thesis in Western Washington University's Department of Psychology (see References). For two years, Elke attended Western as a Fulbright student from West Germany. Her cheerful devotion to the project was total and unrelenting. My Presidential Address benefited greatly from her unselfish efforts and commitment.

\section{Recommended Citation}

Lonner, W. (2016). The Introductory Psychology Text and Cross-Cultural Psychology: Beyond Ekman, Whorf, and Biased I.Q. Tests. Online Readings in Psychology and Culture, 11(1). https://doi.org/10.9707/2307-0919.1145 


\section{The Introductory Psychology Text and Cross-Cultural Psychology: Beyond Ekman, Whorf, and Biased I.Q. Tests}

\section{Abstract}

This article is a reprint of the following paper: Lonner, W. J. (1989). The introductory psychology text and cross-cultural psychology: Beyond Ekman, Whorf, and biased I.Q. tests. In D. Keats, D. Munro, \& L. Mann (Eds.), Heterogeneity in cross-cultural psychology. (pp. 4-22). Lisse, The Netherlands: Swets and Zeitlinger. Some small changes and format modifications were applied.

\section{Creative Commons License}

\section{(c) (i) $(9)$}

This work is licensed under a Creative Commons Attribution-Noncommercial-No Derivative Works 3.0 License. 


\section{Introduction}

The first part of the title of this paper broadly hints that it will be concerned with cross-cultural psychology's place in introductory psychology texts. The meaning of the second part of the title is only partially self-evident. It concerns the fact that the beginning psychology student's exposure to culturally mediated variations in human behaviour is generally explained by a rather narrow selection of many possible topics. These include cultural variations and universals in the facial expression of emotion (Ekman and other neo-Darwinists), linguistic relativity and all those Eskimo words for snow (thanks largely to B. L. Whorf and E. Sapir), and of course, the bias, and hence, unfairness of the ubiquitous I.Q. test. The general intent of this paper is to argue that introductory texts could easily go beyond such predictable coverage, and that the authors of beginning texts should consider it a challenge to consult the contemporary cross-cultural literature for more interesting and timely examples when explaining cultural variations in behaviour to students taking the beginning course in psychology. For some reason or reasons, our efforts have not trickled down to the level of the impressionable.

\section{Background, Rationale, and Purposes of the Study}

Like most members of the International Association of Cross-Cultural Psychology (IACCP), I have had an ongoing interest in cross-cultural psychology's influence on the field of psychology. While the cross-cultural method has been around nearly as long as psychology itself, cross-cultural psychology, as an organised perspective, is fairly new. However, the main thrusts - IACCP, the Journal of Cross-Cultural Psychology (JCCP), the six-volume Handbook of Cross-Cultural Psychology, the International Journal of Psychology, various influential books, and many impressive studies - have been around long enough to make an impact. Yet, we really do not know what this impact is. One way to gauge such influence is through how the results of cross-cultural research are integrated and diffused in the general psychological literature. Another way is to assess how it is handled in introductory texts, and this is the focus of this paper: an analysis of how culture-related material is handled as opposed to perhaps how it could be handled in introductory texts.

Two separate but related projects were completed for this purpose. The first project was a content analysis of 35 current psychology texts. This is the "what is" part of the project, and is a detailed documentation of contemporary treatment of cultural and cross-cultural topics in beginning texts. The second project was a survey of over 30 cross-cultural experts concerning what kind of general or specific cultural or cross-cultural content they think "could be" or "should be" in introductory texts. 
Table 1

Alphabetical Listing of Authors of Texts of the 35 Texts Included in the Analysis (Dates of Publication in Parentheses)

\begin{tabular}{ll}
\hline Atkinson, Atkinson, Smith, and Hilgard (9th & $\begin{array}{l}\text { Lerner, Kendall, Miller, Hultsch, and Jensen } \\
(1986)\end{array}$ \\
Ed.) (1987) & $\begin{array}{l}\text { Morgan, King, Weisz, and Schopler (7th Ed.) } \\
\text { Benjamin, Hopkins, and Nation (1987) }\end{array}$ \\
$\begin{array}{l}\text { Myers (1986) } \\
\text { Bernstein, Roy, Srull, and Wickens (1988) }\end{array}$ & $\begin{array}{l}\text { Ornstein (2nd Ed.) (1988) } \\
\text { Bower, Bootzin, Zajonc, and Hall (1987) }\end{array}$ \\
Carlson (2nd Ed.) (1987) & Parham (1988) \\
Crooks and Stein (1988) & Price, Glickstein, Horton, Sherman, and Fazio \\
& (2nd Ed.) (1987) \\
Davidoff (3rd Ed.) (1987) & Rathus (3rd Ed.) (1987) \\
Doyle (1987) & Sacuzzo (1987) \\
Dworetzky (3rd Ed.) (1988) & Santrock (1986) \\
Feldman (1987) & Scarr and Vander Zanden (5th Ed.) (1987) \\
Gerow (1986) & Simons, Irwin, and Drinnin (1987) \\
Gleitman (2nd Ed.) (1987) & Smith, Sarason, and Sarason (3rd Ed.) (1986) \\
Huffman, Vernoy, and Williams (1987) & Spear, Penrod, and Baker (1988) \\
Kagan and Segal (6th Ed.) (1988) & Wade and Tavris (1987) \\
Kalat (1986) & Wallace, Goldstein, and Nathan (1987) \\
Landy (2nd Ed.) (1987) & Worchel and Shebilske (2nd Ed.) (1986) \\
Lefton and Valvatne (3rd Ed.) (1988) & Wortman and Loftus (3rd Ed.) (1988) \\
& Zimbardo (12th Ed.) (1988) \\
\hline
\end{tabular}

\section{Purposes of the Projects}

The two projects served four purposes. The immediate purpose is this address, allowing me, as it does, to say a few things about cross-cultural psychology and its influence. This topic is consistent with two of my major interests in cross-cultural psychology: how it can be taught more effectively and how it is integrated in the psychological literature. The second purpose concerns the development of course materials. I have found these two projects to be very helpful in organizing thoughts about courses that I teach, including cross-cultural psychology and, in particular, introductory psychology courses which, like many members of IACCP, I routinely teach.

The third purpose of the projects is to stimulate IACCP members to think about what the results of these projects mean and what, if anything, we should do about it. I have found that cross-cultural psychologists have strong opinions about how their most important 
source of professional identification should be handled in psychological literature and in curricular content. The fourth purpose is to give information to authors and publishers of at least the 35 texts involved in the analysis. Copies of a report will be sent to them as well as to those who participated in my recent survey.

\section{The Cultural Content of Introductory Psychology Textbooks}

For the analysis of cultural content, 35 basic psychology texts were selected. All were published in or later than 1986, and most were published in 1987 and 1988. Their selection was somewhat random, but on the basis of conversations with book representatives, they probably accounted for over $75 \%$ of sales of introductory psychology texts in the Englishspeaking world. They represent about one-third of the approximately 90 texts of this kind that are currently available. Several have been translated, and many are available as international editions. Table 1 gives an alphabetical listing of the authors of the texts and their publication dates.

\section{Method of Content Analysis}

The first step in the content analysis was to identify and name the topical categories under which any psychological topic could be indexed. Using tables of contents of many texts, we identified 22 categories. These categories, presented alphabetically in Table 2, are essentially "generic" chapter titles. The typical introductory text contains 16 to 18 chapters. The next and most time-consuming step was to find, in each text, all material that in some substantive way dealt with cultural factors. To this end, we used terms and concepts that are often found in the subject index of texts. These terms and concepts included those listed in Table 3. However, our search for relevant material was not limited to a search of the indexes. Realizing that all indexes are not necessarily perfect reflections of content and therefore not uniformly helpful, appropriate chapters or sections were checked carefully for cultural content even if the index suggested there was no coverage of a particular topic. For example, chapters dealing with abnormal behaviour were routinely and systematically searched for culture-relevant material, especially if the index was not clear about such coverage. Through the establishment of careful procedures and student involvement in the search, we are confident that we found all but the most obscure or trivial relevant material in all 35 texts. We were especially wary about problems that could affect finding the material and putting them into the proper topical categories. We therefore borrowed some procedures and guidelines from signal detection theory in an effort neither to "underinclude" nor to "overinclude" the extent to which the target topics were included in the texts.

We were also sensitive about the variability of the indexes and what this may mean. Some indexes are much more complete and detailed than others. We are aware that professional indexers rather than the author may compile the index; hence a "noninclusive" index may not be an indication of the author's lack of interest in our target concepts. However, as mentioned above, our search was not guided exclusively by the indexes. 
Online Readings in Psychology and Culture, Unit 11, Subunit 1, Chapter 4

Table 2

Alphabetical Listing of Topical Categories Found in Introductory Texts in Psychology often as Chapter Titles

\begin{tabular}{|c|c|}
\hline 1 Abnormal behaviour (psychopathology) & 12 Language and language development \\
\hline $\begin{array}{l}2 \text { Biological factors (brain and nervous system, } \\
\text { genetics) }\end{array}$ & 13 Learning (classical, instrumental \\
\hline $\begin{array}{l}3 \text { Cognition and thought (information } \\
\text { processing, problem solving, creativity) }\end{array}$ & 14 Memory and forgetting \\
\hline $\begin{array}{l}4 \text { Commentary on cultural influences } \\
\text { (statement of at least a full paragraph) }\end{array}$ & $\begin{array}{l}15 \text { Motivation (hunger, thirst, sex, } \\
\text { achievement, intrinsic) }\end{array}$ \\
\hline $\begin{array}{l}5 \text { Developmental (infancy, childhood, } \\
\text { adolescence) }\end{array}$ & $\begin{array}{l}16 \text { Personality (theories, personality } \\
\text { measurement) }\end{array}$ \\
\hline 6 Developmental (adulthood, aging, death) & $\begin{array}{l}17 \text { Psychotherapy and healing (counseling, folk } \\
\text { healing) }\end{array}$ \\
\hline 7 Emotion (facial expression) & $\begin{array}{l}18 \text { Sensation and perception (vision, hearing, } \\
\text { other senses) }\end{array}$ \\
\hline 8 Environmental (personal space, pollution) & $\begin{array}{l}19 \text { Sexuality (sex roles, sex typing, male- } \\
\text { female differences) }\end{array}$ \\
\hline 9 Evolution (Darwinism, human nature) & $\begin{array}{l}20 \text { Social psychology (conformity, stereotypes, } \\
\text { prejudice, attitudes) }\end{array}$ \\
\hline 10 Industrial/Organisational (work, leadership) & $\begin{array}{l}21 \text { States of consciousness (Transcendental } \\
\text { Meditation, dreams, hypnosis, drugs and } \\
\text { alcohol) }\end{array}$ \\
\hline $\begin{array}{l}11 \text { Intelligence (including IQ testing and } \\
\text { measurement of individual differences) }\end{array}$ & 22 Stress, adaptation, and coping \\
\hline
\end{tabular}

Virtually every page of all the texts was searched for relevant material. We were also occasionally concerned about the author's intention. For instance, in one text there was an interesting discussion of Japanese hemispheric lateralisation. We were not certain if the author was merely emphasizing a point about cortical structure or about differences in learning, as opposed to being centrally concerned about cultural variations and the reasons for them. We were also occasionally concerned about some coverage that was so brief that the author's intention was unclear.

\section{Limitations and Constraints of the Method}

One must keep in mind that our sample consisted of English language texts written largely by American psychologists whose target audience primarily consists of hundreds of thousands of North American students. It was beyond the framework of this study to consider 
non-English texts. It would, however, be quite interesting to analyse the cross-cultural content of non-English introductory texts, and especially texts developed from within a country rather than merely translated and adapted. An author's construct system and how he or she approaches basic psychology will at least be partly influenced by his or her culture. Another constraining factor concerns the purpose of introductory texts. What are the motives of the authors? While factors such as these will be discussed in more detail later, we were concerned about several questions. For instance, is there space in introductory texts for extensive culture-related material? Are authors and publishers sincerely motivated to include such material? To what extent should we expect students to understand and assimilate culture-related material if many of them are not ready or experienced enough to consider the details or implications of cultural variations of human behaviour?

Table 3

Terms and Concepts Systematically Searched for in the Texts

\begin{tabular}{ll}
\hline $\begin{array}{l}\text { Abnormality (definitions, models of culture) } \\
\text { Acupuncture }\end{array}$ & $\begin{array}{l}\text { Ethnocentrism (including ingroup-outgroup) } \\
\text { Facial expression (cross-referenced with } \\
\text { emotion and culture) }\end{array}$ \\
$\begin{array}{l}\text { Adolescence (including attractiveness, initiation } \\
\text { rites) }\end{array}$ & $\begin{array}{l}\text { Nature versus nurture } \\
\text { Childhood (culture's influence on, cognitive } \\
\text { development, Piagetian research }\end{array}$ \\
$\begin{array}{l}\text { Consciousness and its altered states (through } \\
\text { alcohol, drugs, meditation, and culture) }\end{array}$ & $\begin{array}{l}\text { Personal space } \\
\text { visuallusions) }\end{array}$ \\
$\begin{array}{l}\text { Cross-cultural (as a specific entry in the index, } \\
\text { with its subindices, if any) }\end{array}$ & $\begin{array}{l}\text { Prejudice, stereotypes, and related social } \\
\text { psychological terms }\end{array}$ \\
$\begin{array}{l}\text { Culture (as a specific entry in the index, with its } \\
\text { subindices, if any) }\end{array}$ & $\begin{array}{l}\text { Whorf-Sapir (or Whorfian, or Sapir-Whorf) and } \\
\text { psycholinguistics, language development, } \\
\text { cognition }\end{array}$ \\
\begin{tabular}{l} 
Ethnicity \\
\hline
\end{tabular}
\end{tabular}

\section{Results}

When we considered the raw frequency of coverage of the 22 topical categories listed in Table 2, it was clear that four of them dominate. Discussion of intelligence and its measurement (category 11) appear in all 35 texts. It is unlikely that any current introductory text does not include at least some material on topics such as racial or ethnic factors in intelligence or the biased nature of most so-called intelligence tests. 
Coverage of emotion and culture, especially involving popular research by Ekman and his neo-Darwinian colleagues that supports universality in the facial expression of emotions, also received extensive attention. Such material was found in 33 of the texts. Also appearing in 33 texts were culturally relevant social psychological topics. However, this topical coverage mainly included general topics such as racial prejudice, cultural stereotypes, and ethnocentrism, with only occasionally mentioning specific cultural groups under such topics.

Also receiving extensive coverage were various factors under the topical heading of language and language development. Specifically mentioned in 29 of the texts was the Whorfian, or Whorf-Sapir, hypothesis of linguistic relativity. Here, the major theme was the extent to which language may shape how "reality" is perceived and how people think.

After such frequent coverage in these four areas, there was a considerable drop. For instance, the next two categories of coverage were in the developmental area, especially with respect to the influence of Piaget in looking at developmental processes across cultures, which was mentioned with varying degrees of depth and sophistication in 24 texts, and in the topical analyses, among the lowest third of the texts in terms of such coverage. It included culture-related material in just seven of the 22 categories.

\section{References to Classics, Productive Authors, Organisations, and Publications}

A number of journal articles and books can be regarded as cross-cultural classics. Such research is very familiar to cross-cultural psychologists and has been quite effective in influencing the general character of research in different substantive areas. Although not exhaustively and systematically, the 35 texts were searched to determine the extent to which such classics were cited in them. Leading the citations was Segall, Campbell, and Herskovits' (1966) book concerning cultural and ecological influences on visual perception, which was cited in seven (20\%) of the texts. And what has been perhaps the most widely cited journal article in cross-cultural psychological research, Berry (1966) was mentioned in just one of the texts. These limited citations indicate that for some reason, the authors of introductory texts are missing numerous key research reports and books that are central to a cross-cultural perspective in psychology.

Similarly, the work of the most productive authors in cross-cultural research is seldom mentioned in basic texts. We identified approximately 40 authors known for their substantial contributions to cross-cultural research and sensitivity to cultural variations in behaviour. These individuals included famous anthropologists such as Ruth Benedict (three mentions) and Margaret Mead (10 mentions) and, more appropriately for our present purposes, several of the more productive members of our association such as John Berry, Richard Brislin, Pierre Dasen, Juris Draguns, and Harry Triandis, each of whom was referenced only once (less that 3\%) in one of the texts. Of all members of our association, Jan Deregowski leads in citations, having been cited seven times, and always for his cross-cultural research on perception. Ekman and his colleagues clearly lead the citation parade with frequent mentions in nearly every text; a distant second is Whorf, who was referenced in 22 of the texts. 
A third way to assess the extent of cross-cultural coverage in introductory texts is through the frequency with which they cite publications that are centrally important to crosscultural psychology. Among numerous books and a few journals in the area, five can be singled out as representing the leading sources of information: Studies in cross-cultural psychology (Warren, 1977), Handbook of cross-cultural human development (Munroe, Munroe, \& Whiting, 1981), the six-volume Handbook of cross-cultural psychology (Triandis, 1980), the International Journal of Psychology (which began in 1966), and the Journal of Cross-Cultural Psychology (inaugurated in 1970). Together, these publications are gateways to a whole world of cross-cultural material and literally thousands of cross-cultural research reports. Yet, we found a total of only eight references to these publications spread across just six of the 35 texts, and two texts contained five of the eight citations. To devoted cross-culturalists, these are startling statistics, and are made even worse by the fact that there is absolutely no mention in any of the texts of organised international cross-cultural efforts. For instance, none of the texts mentions the IACCP or any other specific organisation or group that is explicitly concerned with psychology in broad cultural perspective. A whole generation of students are not being made aware, early in their education, that a growing number of psychologists and publications are actively involved in psychological research from an international, universalistic perspective.

\section{Some Conclusions and Implications of this Analysis}

This analysis of the cultural and cross-cultural content of 35 contemporary introductory psychology texts shows that such coverage is rather thin, somewhat predictable, repetitive, and makes very little use of extensive contemporary cross-cultural research that has been reported in many different publications. There are a number of factors that by themselves or in combination might account for such scant coverage.

1. The authors of introductory texts, like so many psychologists, may believe in the essential validity and generaliseability of nearly all psychological theories and principles. This may be a benign form of ethnocentrism - benign because there is no malicious intent to subordinate or ignore cross-cultural research, and ethnocentric because it may not be considered important to report research about human behaviour in other cultures. However, the fact that all texts have at least some culture-relevant material minimises blatant ethnocentrism and cultural myopia as a strong reason for limited inclusion of this type of material.

2. It is difficult enough to explain behaviour in one's own culture in psychological terms in rather limited space, let alone try to explain frequent and perhaps very subtle influences on behaviour in many other cultures. Many authors may not want to complicate things by systematically adding the cultural variable. Other areas of psychology - for instance learning, personality, and biological processes - are usually not covered in great depth. Consequently, many authors may feel no great need to concern themselves with the cultural variable in other than superficial and very general ways.

3. Authors may feel that there is insufficient room for anything but the basics in beginning texts. Psychology is a huge field and getting larger. Publishers probably demand great 
range of coverage to be competitive in the academic marketplace, and culture may be squeezed out or assigned low priority by the publishers and not the authors. Other groups or organised efforts may also feel underrepresented, so there may be little reason for the cross-cultural establishment to feel particularly overlooked or short-changed. If all "special interest groups" (e.g. forensic psychology, environmental psychology, psychology and religion, ad infinitum) were to receive substantial attention, an introductory text would have to be impossibly large. However, cross-cultural psychology, unlike other "special interest groups," cuts across all of psychology, while most other groups are rather focused and limited.

4. The authors of beginning texts may not be very familiar with other cultures and ethnic groups, and in particular they may be unaware of the extensive cross-cultural literature and where to find it. This would of course mean that they would not be aware of the IACCP and all of its efforts. Consequently, culture-related material may recieve limited attention because authors may not have the right kind of material at their disposal when they are writing or revising their texts. If this is the case, our association might consider ways to make our collective efforts more visible and accessible.

5. Students, and perhaps in particular, American students, may lack the constructs necessary to accomodate cross-cultural material. A recent poll conducted by the Gallup organisation and the National Geographic Society showed that American students are frighteningly ignorant about geographic facts. For instance, one in seven Americans between the ages of 20-24 could not find the U.S. on the map, $75 \%$ could not locate the Persian gulf, and one in four could not find the Pacific Ocean. Similar bleak statistics indicted the geographic knowledge of students from other countries. This ties in somewhat with observations made in an unpublished study by Vander Goot (1987). Vander Goot tried to integrate cross-cultural and minority concerns into her introductory psychology courses at Calvin College in Michigan. As Rumpel (1988) reported, Vander Goot found that students tended to discount any examples dealing with with unfamiliar groups or cultures and to take more familiar examples more seriously. She says that because students lack experience they do not have the constructs into which they can assimilate materials concerning persons unfamiliar to them. This point is consistent with the comment made by Cushner (1987) that it is difficult to teach culture-related concepts to students who have limited exposure to relevant experiences.

As a consequence of such widespread ignorance about cultural material and geographic myopia, authors of texts may simply be rather reluctant to introduce some subtleties of cultural variation in human behaviour for fear of not hitting the mark. Or, to use psychological jargon, authors may not feel that they will be reinforced for the inclusion of such material (with the main reinforcers being student adulation and understanding) and hence include only some of the more easy to understand and inherently interesting material that is instantly grasped and that can be introduced with pictures and cute examples. This is probably why Ekman's research is found in nearly all texts, and why the Whorfian hypothesis is nearly as popular. 
A few other things should be taken into consideration. Included in this report are facts, suggestions, and examples, and not prescriptions for change and specific recommendations for remediation. I do not want to dictate content, or even to coerce in subtle ways authors of basic texts to include culture-related material, and I certainly do not want the results of this study to be construed as representing IACCP's official position. This is basically a descriptive archival study instigated by my own motives, in which the facts may speak for themselves. Interpretations of this analysis, as well as any implications it may have, may vary considerably from author to author. A few key questions can also be asked: What do crosscultural psychologists want, eventually? Should members of IACCP develop missionary zeal and not stop until the cultural content of all texts in psychology receives necessary and fair attention? Or is everything going acceptably well? After all, there have been frequent reviews of cross-cultural psychology in important "mainstream" outlets such as the American Psychologist (for instance, the September, 1984 issue) and the Annual Review of Psychology, and there has been a constant stream of cross-cultural books and other publications during the past fifteen or twenty years, extending to conferences, meetings, and symposia with cultural themes abound. The problem, it seems, is focused on the undergraduate level, the level of the beginning student. They are not being introduced early enough to cultural variables and their effect on human behaviour. They are not being told to "think cross-culturally" or "in universalistic terms" early enough. Perhaps authors of introductory texts are depending upon others to do the cross-cultural education during the latter stages of their students' education. If so, perhaps this is a misguided strategy.

Everything we know about learning indicates that nothing can replace early exposure to concepts and phenomena, so that they slowly but surely can become integrated into the ways in which people think about the world beyond their narrow borders. But can crosscultural coverage really be "adequate" in a basic psychology text? In such limited space, can authors go much beyond the ubiquitous Ekman (who is not even a member of IACCP), Whorf (who is dead), and the issue of biased I.Q. tests (which is dying)? Maybe the only way to satisfy cross-culturalists would be to publish an introductory text built explicitly around a universalistic theme and/or one that takes into account the voluminous cross-cultural literature whenever possible and not rely so heavily on standard and hackneyed examples that are so prevalent in texts today. Our hats should be off to any author who can make the best use of much of the current literature and general goals and aspirations of cross-cultural psychology and incorporate such material in their new or revised basic texts.

\section{Survey of Experts in Cross-Cultural Psychology}

Rumpel (1988) and I have documented that cultural and cross-cultural material in current English-language introductory psychology texts is spotty and variable, and that much of the limited coverage is generally predictable. Current material is not mentioned much, and references to books, journals, and other efforts that are consistent with the goals of IACCP are very rare. And above I have outlined several reasons why authors of introductory texts may not much culture-related material. So what can be done about this? In an effort to try 
and determine what specific kinds of cross-cultural material could be in introductory texts, as opposed to what is already in them, a survey of experts in cross-cultural psychology was conducted. As mentioned early in this address, this survey constitutes the second of two highly related projects that were designed to assess this situation. Thirty-four cross-cultural psychologists were asked to participate in the survey. Individuals in this judgmental sample, all of whom are members of IACCP, were selected because of their contributions to and familiarity with cross-cultural psychology. All but two of them responded. The participants were sent a letter seeking advice about what to include in a hypothetical introductory text being prepared. It was explained that the author of this planned text wanted to include as much good and contemporary cross-cultural material as possible. Participants were asked to list as many as 10 suggestions concerning what they think should be considered candidates for inclusion. It was explained that the items, concepts, studies, frameworks, and so on could come from any one or more of four areas: the conceptual, the factual, the methodological, and the organisational. The basic idea was to have them list (and not rank) up to 10 items that they considered prime candidates for inclusion in a forthcoming introductory text.

I realize that this task has some shortcomings and limitations. One of them is that a person's responses may vary if he or she completed the task at different times. For instance, what one has been reading lately or one's fluctuating moods and preferences may have a strong effect on one's list. However, while it is true that the choices an individual makes might vary across occasions, when lists are summed and collated across many individuals, variability should give way to increasing stability as a function of sample size.

\section{An Overview of the Results}

A full report containing the results of the survey will be sent to the authors of the 35 texts that were included in the first project. They, much more than dedicated cross-cultural psychologists, are the ones who may benefit most from the results of the survey. An uninformed author cannot be involved in change. Consequently, only a brief summary of the results is included here because of space constraints. When the lists were received from the participants, each separate item was written on an index card. This resulted in a total of 297 cards (320 cards were possible - 10 each from the 32 respondents - but a few individuals listed only five or six items). I then sorted all cards into as many separate piles (categories) as deemed necessary; this process resulted in the formation of 21 relatively homogeneous piles of cards. Table 4 lists these piles in descending order of frequency ( $N$ s are given in parentheses).

A summary of the basic content of several of the 21 categories will give a flavour of the implicit and indirect recommendations that cross-cultural experts might give to authors of introductory texts in terms of what coverage might be considered.

Forty of the 297 responses (a little more than 13\%) were placed in the "methodological" pile. Here, the experts considered it important for students to be informed that cross-cultural psychology is a major method. They also suggested outlining the difficulties that are associated with establishing equivalence, and that a discussion of the 
familiar "etic-emic" problem would be instructive. Some respondents, however, suggested that despite the importance of understanding the various methodological difficulties and their possible solutions, they would be reluctant to attempt to explain such complex and sophisticated material to beginning students. The second most frequently mentioned area encompassed social psychological variables, where 37 (just under 13\%) of the responses were placed. It was frequently mentioned that Hofstede's (1980) research on work-related values merits mention in introductory books as a good example of interesting cultural variations on meaningful dimensions, coupled with numerous plausible explanations. The current "hot" topic of idiocentrism vs. allocentrism as person-level variables (individualismcollectivism at the whole cultural level) was mentioned by many; certainly some of the current research in the area could be consulted (e.g., Hui and Triandis, 1986). Also, ethnocentrism was mentioned frequently - not usually as a classical substantive social psychological topic, but rather as a characteristic shared by many researchers in social psychology who typically use a very narrow database when explaining social psychological phenomena. Thus, ethnocentric bias in social psychological research could be discussed (Bond, 1988).

\section{Table 4}

Categories Into Which the 297 Survey Response Items Were Sorted

1 Methodological factors and considerations (40)

2 Social psychological variables (e.g., attitudes, values, ethnocentrism) (37)

3 General rationale for and value of crosscultural research (32)

4 Child development, child rearing (26)

5 Perception as influenced by culture and ecology (18)

6 Cognition (memory, problem solving, thinking) (15)

7 Abnormality, mental health issues, and culture (13)

8 Organisational and structural factors in crosscultural psychology (IACCP, JCCP, various books and meetings) (13)

9 Cognitive style (especially field dependence/independence) (12)

10 Intercultural interaction (culture training, cultural familiarisation) (12)

11 Cognitive development (11)
12 Intelligence (definitions, measurement, cultural variations) (10)

13 Language and linguistics (10)

14 Ethnicity and ethnocentrism in cross-cultural research (8)

15 Acculturation and social change (7)

16 Paralinguistics (non-verbal communication)

17 Culture and self (variations in self-definition)

(4)

18 Study of indigenous psychologies (4)

19 Sex differences and culture (3)

20 Study of ethnic minorities in various cultures

21 Responses that are hard to classify and do not fit into any of the above categories (14) 
The third most popular cluster of responses involved introducing students to the general reasons why cross-cultural research is important. Here, for instance, it could be explained, as Triandis and Brislin (1984) and many others have done, that including other cultures in a research design extends the range of variation of the independent variable, thereby making it more possible, eventually, to develop a "universal" psychology - or at least a psychology that has reached out to other cultures. Students should also be told that by going into other cultures, psychology would increase the chances of discovering cultural and ecological factors that have been overlooked by the "mainstream" for years. Students could also be told that another advantage of cross-cultural psychology is that it tends to increase intercultural sensitivity and prepares one for international travel. Respondents often mentioned that the topics of child rearing and child development and numerous cultural variations in this area are ripe candidates for inclusion in beginning books. Specifically mentioned was the Piagetian perspective (e.g. Dasen, 1977), the work of the Whitings (Whiting \& Whiting, 1975), and the wide-ranging edited book by Munroe et al. (1981). Advice here was along the lines of Torney-Purta's (1984) recommendations about how to infuse social and developmental courses with relevant cross-cultural material.

Responses that involved a few other categories can be briefly mentioned in this limited space. For example, about half the respondents recommended that introductory text authors explain to beginning students that there are serious, organised efforts to consider cultural factors extremely important in the general conduct of psychological research. Mentioned specifically were our association and the Journal of Cross-Cultural Psychology.

Another area receiving attention was the Witkinian perspective on culture and cognitive style. Although research in this area has declined somewhat in recent years, it still is one of the most productive and interesting paradigms in cross-cultural psychology. Despite this, it was not mentioned even once in any of the 35 texts scrutinised for their cultural content. Authors of beginning texts would be well-rewarded by reviewing basic resources in this domain (e.g., Witkin \& Berry, 1975; Witkin \& Goodenough, 1981), mainly because it represents a very interesting way to look at how culture and ecology combine to affect an individual's characteristic mode of functioning.

A final example of the kind of coverage that respondents recommended is the work on culture training and intercultural interaction (the 10th item on the list given in Table 4). A number of cross-cultural psychologists have developed various techniques that are useful in preparing people to live in other cultures more effectively and more happily, or to experience more productive interaction when dealing with people from other cultures. The recent book by Brislin, Cushner, Cherrie, and Young (1986) is an interesting example of this genre of applied cross-cultural psychology, the essence of which would make interesting reading for the typical introductory student. 


\section{Summary and Concluding Comments}

\section{Five Points will Summarise What I Have Said}

1. Coverage of cultural and cross-cultural material in introductory texts is variable, generally quite limited, and predictable; some topics are found in nearly all texts, and there is little evidence to suggest that many authors of introductory texts are consulting current crosscultural literature.

2. Several reasons why there is limited use of cultural and cross-cultural material in beginning texts were outlined, and any one or more of these reasons may account for such limited coverage.

3. The survey of experts reveals numerous suggestions for text authors to consider in terms of future coverage. There are many discrepancies between what is in texts as opposed to what might be in them.

4. The IACCP's role in this matter probably should rely on a continuing evolution of the cross-cultural method, and not a big revolution such as a quick and major shake-up in how authors of introductory texts approach their writing. Moreover, neither I nor the IACCP should be so presumptuous as to try and "dictate" or force change. Rather, at every opportunity, we should advise writers of basic texts that there is a wealth of interesting cross-cultural resources available and encourage their use.

5. Similar text analyses across individuals, countries, and times are encouraged, as are different surveys. It is nearly certain that no two cross-cultural psychologists will produce identical lists of cross-cultural material or topics that they think should be included in introductory texts. However, there are some commonalities, and cross-cultural psychology has much valuable and interesting material which merits serious consideration. It would be interesting to conduct similar projects in five or ten years to determine the extent to which we have influenced how authors of introductory texts acquaint beginning students with cross-cultural psychology and all that it has to offer. Perhaps we will see a gradual move away from standard, time-worn examples of cultural variations on psychological dimensions and more movement toward the inclusion of many interesting examples, reflecting the great diversity there is within cross-cultural psychology. The IACCP should be ready to assess such change and should be pleased when the desired changes take place.

\section{References}

Berry, J. W. (1966). Temne and Eskimo perceptual skills. International Journal of Psychology, 1(3), 207-229. http://dx.doi.org/10.1080/00207596608247156

Bond, M. H. (Ed.). (1988). The cross-cultural challenge to social psychology. Newbury Park, CA: Sage Publications.

Brislin, R. W., Cushner, K., Cherrie, C., \& Yong, M. (1986). Intercultural interactions: A practical guide. Newbury Park, CA: Sage Publications. 
Cushner, K. H. (1987). Teaching cross-cultural psychology: Providing the missing link.

Teaching of Psychology, 14(4), 220-224.

http://dx.doi.org/10.1207/s15328023top1404 7

Dasen, P. R. (Ed.). (1977). Piagetian psychology: Cross-cultural contributions. New York, NY: Gardner Press.

Hofstede, G. (1980). Culture's consequences: International differences in work-related values. Newbury Park, CA: Sage Publications.

Hui, C. H., \& Triandis, H. C. (1986). Individualism-collectivism: A study of cross-cultural researchers. Journal of Cross-Cultural Psychology, 17(2), 225-248. http://dx.doi.org/10.1177/0022002186017002006

Munroe R. L., Munroe, R. H., \& Whiting, B. (1981). Handbook of cross-cultural human development. New York, NY: Garland.

Rumpel, E. (1988). A systematic analysis of the cultural content of introductory psychology textbooks. Unpublished master's thesis. Western Washington University: Bellingham.

Segall, M., Campbell, D., \& Herskovits, M. (1966). The influence of culture on visual perception. Indianapolis, IN: Bobbs Merrill.

Torney-Purta, J. (1984) Annotated bibliography of materials for adding an international dimension to undergraduate courses in developmental and social psychology. American Psychologist, 39(9), 1032-1042. http://dx.doi.org/10.1037/0003066X.39.9.1032

Triandis, H. C. (1980). Handbook of cross-cultural psychology (Vols. 1-6). Boston, MA: Allyn and Bacon.

Triandis, H. C., \& Brislin, R. W. (1984). Cross-cultural psychology. American Psychologist, 39(9), 1006-1016. http://dx.doi.org/10.1037/0003-066X.39.9.1006

Vander Goot, M. (1987). Cross-cultural and minority concerns. Unpublished manuscript, Calvin College, Grand Rapids, MI.

Warren, N. (Ed.). (1977). Studies in cross-cultural psychology (Vol. 1). New York, NY; London, England; San Francisco, CA: Academic Press.

Whiting, B., \& Whiting, J. W. M. (1975). Children of six cultures: A psychocultural analysis. Cambridge, MA: Harvard University Press.

Witkin, H. A., \& Berry, J. W. (1975). Psychological differentiation in cross-cultural perspective. Journal of Cross-Cultural Psychology, 6(1), 4-87. http://dx.doi.org/10.1177/002202217500600102

Witkin, H. A., \& Goodenough, D. R. (1981). Cognitive style: Essence and origins. New York, NY: International Universities Press. 


\section{Note to the reprint}

The editors of the Online Readings in Psychology and Culture (ORPC) attempted to contact the Dutch-based company, Swets \& Zeitlinger, to request permission to reprint this chapter. However, the publisher has declared bankruptcy in September 2014 and is now officially defunct. Our rationale to use the rules of "fair use" are as follows:

The item was published in 1989 as the written version of the required presidential address given by Walter J. Lonner, who in 1986-88 was closing out his two-year term as president of the International Association for Cross-Cultural Psychology (IACCP). Lonner is the founding editor of the ORPC and a continuing member of its editorial board. The ORPC is a non-profit open-access electronic resource, and is offered free of charge for students and scholars throughout the world. Owned by IACCP, its sole intent is to inform students, teachers, and researchers about current knowledge in psychology and culture, especially as described in a wide array of introductory psychology texts. It is essentially a not-for-profit teaching aid.

This reprinted chapter is a small part (18 pages) of the entire (580 Pp) book, which was copyrighted in 1989. The title of the book is Heterogeneity in cross-cultural psychology: Selected papers from the ninth international conference of the International Association for Cross-Cultural Psychology. It was edited by D. M. Keats, D. Munro, and L. Mann. As the purpose, nature, amount, and effect speak in favor of fair use, we decided to publish this paper under the rules of fair use. The paper is considered important in the present context, largely for comparative historical purposes that is of central interest to the study of psychology and culture. 